DOI: $10.17805 /$ zpu.2015.4.25

\title{
Идеал у Достоевского и Шекспира
}

\author{
К. А. СТЕПАНЯН \\ (ЖУРНАЛ «ЗНАМЯ», Г. МОСКВА)
}

В статье анализируются представления классиков русской и английской литератур - Ф. М. Достоевского и У. Шекспира - о возможности и способах победы над смертью, над злом в человеческой душе, о вероятности устроения счастливого будущего человечества на Земле, в пределах земной истории. Тему эту предполагается раскрыть главным образом на основе «фантастического рассказа» «Сон смешного человека» Ф. М. Достоевского и «Сна в летнюю ночь» и «Бури» У. Шекспира.

Формы сна и фантастики издавна использовались в литературе для максимально полной и свободной демонстрации авторского идеала (либо для предупреждения о возможном торжестве антиидеала). Но у подлинных (метафизических) реалистов Достоевского и Шекспира мы скорее имеем дело с глубоким анализом трудностей и препятствий, лежащих на пути к человеческому счастью.

Названные произведения рассмотрены в контексте всего творчества Достоевского и Шекспира, представлений о «золотом веке» в истории культуры, задачах и возможностях искусства в деле преображения человеческой природы. Проанализированы согласие и спор Достоевского с Шекспиром по обозначенным проблемам, в частности, их разногласие в толковании заповеди «Возлюби ближнего как самого себя» (с учетом сказанного по этому поводу в работах М. М. Бахтина) и вообще феномена человеческой любви.

Анализ показал, что идеал Достоевского - человек как следствие духовной эволюции. Идеал Шекспира проявляется во многом апофатически: люди в его пьесах, живя в христианские времена, во многом продолжают оставаться язычниками, в этом суть их трагической вины. Присутствие Христа ощущается через Его отсутствие. И остается уповать только на милосердие людей друг к другу и всепрощение. 
Ключевые слова: идеал; Ф. М. Достоевский; У. Шекспир; М. М. Бахтин; «Сон смешного человека»; «Сон в летнюю ночь»; «Буря»

Частный человек не может угадать вполне вечного, всеобщего идеала, - будь он сам Шекспир. Ф. М. Аостоевский. Г-н -бов и вопрос об искусстве

\section{BВЕАЕНИЕ}

У Шекспир (наряду с Сервантесом и Шиллером) был для Ф. М. Аостоевского не- пререкаемым художественным авторитетом на всем протяжении творческого пути. Тем важнее для лучшего понимания произведений русского и английского писателей выявить и попытаться сформулировать некий идеал, направлявший их духовные и творческие поиски.

\section{«СОН СМЕШНОГО ЧЕАОВЕКА» - МЕЧТА ИАИ ПРОГРАММА АЕЙСТВИЙ?}

Напомню вкратце содержание этого «фантастического» (определение самого Ф. М. Аостоевского) рассказа из апрельского «Аневника писателя» 1877 г. «Смешной человек», скептический петербургский житель, приходит к убеждению, что ему «все равно было бы, существовал ли бы мир или если б нигде ничего не было» (здесь и далее во всех цитатах слова курсивом выделены автором цитаты; полужирным шрифтом - мною. - K. С.) (Аостоевский, 1983: 105), мало того, и всем вокруг «все равно». Кстати, эта мысль, что вся окружающая действительность - не более чем сон или «скопление паров» (как думает Гамлет), - очень часта у героев-эгоистов Аостоевского и Шекспира, что понятно: когда вся реальность сосредоточивается в тебе самом, на другое и на других ее уже не хватает. Придя к выводу, «что и никогда ничего не будет» (там же: 105), «смешной» решает застрелиться. Но, уже приготовившись к этому и положив пистолет перед собой, он неожиданно засыпает, во сне все-таки застреливается и, уже из могилы, бросает вызов неведомому для него Богу: показать смысл совершающегося с ним. Тогда он оказывается перенесен за тысячи километров и лет на далекую «планету Солнца» - другого, не нашего Солнца, но во всем похожую на нашу Землю и наше Солнце. Вот только живут там абсолютно счастливые, не оскверненные грехопадением люди, находящиеся в гармонии друг с другом и со всем мирозданием. Они с любовью принимают «смешного», и он с восторгом присоединяется к ним. Но кончается тем, что он развращает их всех. После чего они начинают проходить весь многострадальный путь земного человечества, со всеми пороками, кровавыми разделениями, войнами, поклонением науке, которая должна открыть «законы счастья» (там же: 116) и т. А. Однако, проснувшись, он заявляет - себе и читателям что видел «живой образ» Истины, заключающейся в том, что «люди могут быть прекрасны и счастливы, не потеряв способности жить на земле» (т. е. еще в этом мире), и если бы все согласились «любить других, как себя», то «в один бы день, $b$ один бъ час - все бы сразу устроилось» (там же: 118-119) - т. е. и на Земле наступили бы те же счастье и гармония, что он увидел на той планете «по прибытии» туда. Но характерно, что сам «смешной» не очень-то верит в осуществимость этого, понимает, что «не бывать раю», и уж совсем странно: в ответ на возражение, что виденное им - всего лишь сон, вопрошает: «А наша-то жизнь не сон?» (там же: 118).

При внимательном чтении этого рассказа обнаруживается целый ряд и других парадоксов и недоумений. Если изображенное бытие людей на «планете Солнца» есть 
действительно идеал, то насколько же он непрочен, коль один «смешной» петербургский чиновник сумел разрушить его. И почему не они, «дети Солнца», преобразили своего гостя, несмотря на всю их взаимную любовь, а он развратил их всех?

Мы знаем мечту самого Аостоевского (не раз высказанную им в «Аневнике писателя») о том, что земная жизнь человечества не завершится апокалипсическими катастрофами, а «народы заживут одним духом и ладом, как братья, разумно и с любовью стремясь к общей гармонии» (там же: 19). Но каким виделся ему путь к этому?

Мы знаем очень необычную - и в то же время вполне укладывающуюся в христианскую парадигму - мысль Аостоевского о том, что «если все [станут] Христы» (Аостоевский, 1974: 106, 182, 188, 192-193), по слову апостола Павла («Елицы во Христа крестистеся, во Христа облекостеся» - Гал. 3:27), или просто настоящие христиане, то все социальные и экономические проблемы будут враз решены. Но знаем и его запись в ночь смерти первой жены: «Возлюбить человека, как самого себя, по заповеди Христовой, - невозможно. Закон личности на земле связывает. Я препятствует. Один Христос мог, но Христос был вековечный от века идеал, к которому стремится и по закону природы должен стремиться человек» (Аостоевский, 1980: 172). И это стремление может завершиться достижением цели, если произойдет «высочайшее, последнее развитие личности» (там же). Но достижение этой цели всем человечеством Аостоевский относит здесь к «будущей, райской жизни», к постземному существованию. А «на земле человек в состоянии переходном» (там же: 173). Знаем и его мысль из подглавки «Золотой век в кармане» «Аневника писателя» - о том, что если бы собравшиеся в этой вот бальной зале люди узнали, как они на самом деле прекрасны, то враз смогли бы «осчастливить всех <..> и всех увлечь за собой» (Аостоевский, 1981: 13). Но знаем и рассуждения из Подготовительных материалов к «Бесам» о необходимости mpуда православного и о том, что если захотеть все устроить «вдруг», то «дело будет бесовское» (Аостоевский, 1974: 195). А в февральском выпуске «Аневника писателя» 1877 г. Аостоевский пишет: «Осмыслить и прочувствовать можно даже и верно и разом, но сделаться человеком нельзя разом, а надо выделаться в человека. $<$...> ...мыслители провозглашают общие законы, то есть такие правила, что все вдруг сделаются счастливыми, без всякой выделки, только бы эти правила наступили. Аа если б этот идеал и возможен был, то с недоделанными людьми не осуществились бы никакие правила, даже самые очевидные» (Аостоевский, 1983: 47). Тут еще два вопроса: мог бы развратить сообщество Христов «смешной человек» и - обратно - были ли «дети Солнца» «недоделанными людьми»?

Старец Зосима говорит в «Братьях Карамазовых»: «...не было бы драгоценного Христова образа пред нами, то погибли бы мы и заблудились совсем, как род человеческий пред потопом» (Аостоевский, 1976: 290).

Именно отсутствие в мировидении «смешного человека» образа Христа, личностного образа Бога, ставшего человеком и воплотившего в своей земной судьбе реальность победы над страданием и смертью и обретения вечной жизни, позволяет понять, почему «смешной» и после своего сна не верит в рай и готов считать, что вся наша жизнь есть сон. И почему, кстати, М. М. Бахтин считал, что в этом рассказе Аостоевского «господствует не христианский, а античный дух» (Бахтин, 2002: 168): для ученого в этом, как и во многих других случаях, наиболее важным было определить мировидение героя, а не автора. Кроме того, Бахтин ведь полагал, что из нашего мира ушел Христос (Бахтин, 2003: 19), а потому и спорил с заповедью «возлюби ближнего, как самого себя», утверждая, что себя любить невозможно, ибо к себе можно отно- 
ситься только со стыдом или покаянием, а прощение и любовь приходят извне, от трансцендентного Бога (Бахтин, 2003: 117, 126, 132-134, 184).

То же и «смешной»- он пока пережил лишь опыт смерти. Опыт жизни ему еще предстоит. И позволю себе сказать, что главный итог его сна - даже не узнанная им Истина, а обнаружение любви Бога к себе. Аюбви, открывшейся ему через любовь человеческую, как это всегда и бывает у Аостоевского. По сути, волею автора, Аостоевского, и сам «смешной», и мы, читатели, оказываемся здесь участниками мистерии - дарующей, как известно, надежду на бессмертие. И не случайно есть признания читателей, что именно этот рассказ Аостоевского убедил их в существовании вечной жизни.

В мистериальном плане «Сна смешного человека» изображено начало духовного преображения, и в то же время здесь, возможно, отразились так и не преодоленные Аостоевским до конца фурьеристско-социалистические убеждения молодости. Но, думается, и в молодости к утопическим теориям его влекла именно любовь к людям. Эта любовь не позволяла ему и потом сердцем принять все те ужасные испытания, которые, по Апокалипсису, предстоит пережить людям, прежде чем они достигнут Царствия Небесного. Однако опаснейшую близость такого мировидения к «пищеварительной философии» (его определение) он тоже видел лучше многих из нас, равно как и всю глубину греховной уязвимости и пораженности человеческого естества. Кто лучше его знал, что большей частью и народу, и человечеству, к сожалению, нужно пережить ужасную катастрофу, чтобы просто повернуться к Богу. И насчет «золотого века» он никогда не обольщался, понимая, что это всего лишь мечта, «высокое заблуждение» человечества. На заднем плане картины Клода Аоррена «Асис и Галатея», в связи с которой рассуждают о «золотом веке» Ставрогин и Версилов и которую называл «золотым веком» сам Аостоевский, - страшный циклоп Полифем, который вскоре из ревности разрушит безмятежное счастье влюбленных, убив Асиса скалой. Во сне Ставрогина видение «золотого века» сменяется образом «красненького паучка», символа сладострастья, а потом перед его взором возникает погубленная им девочка Матреша.

Видимо, поэтому после попытки создания образа, если можно так выразиться, сразу «положительно прекрасного человека» - князя Мышкина, Аостоевский замыслил написать «Житие великого грешника» - реализацией чего стали три его последних великих романа, с венчающими эту своеобразную трилогию «Братьями Карамазовыми».

Итак, идеал Аостоевского - это человек, любовью и трудом православным одолевший грех, и человечество, достигающее в ходе нелегкой духовной эволюции такого совершенства. Насколько писатель был убежден в осуществимости этого идеала вопрос обширный, требующий для ответа еще не одно исследование.

\section{ШЕКСПИР: ОТЧАЯНИЕ И НАДЕЖАА}

Великие трагедии, показывающие всю ужасающую глубину людского грехопадения и результат действий людей, находящихся в неизбывном плену собственных пороков, - но одновременно в гуманитарном, безрелигиозном сознании имеющих величественный статус героев, бросающих вызов Богу и претендующих на самовольное переустройство мира «по справедливости», - принесли Шекспиру в первом десятилетии XVII в. славу. Но в последние годы жизни Шекспир все больше начинает задумываться над проблемами раскаяния и преображения человека, возможности воскре- 
сения, победы над смертью. В «Перикле», «Цимбелине», «Зимней сказке», «Буре»английский поэт Т. Хьюз называл их «теофаниями» (Хьюз, 2014: 99) - эти проблемы становятся ключевыми. Но сначала остановимся на созданной задолго до того коме$\partial u и$ «Сон в летнюю ночь». В. Г. Белинский писал, что наряду с «Бурей» «Сон в летнюю ночь» представляет собой «совершенно другой мир творчества Шекспира, нежели его прочие драматические произведения, - мир фантастический» (Белинский, 1978: 406). Аругая аналогия со «Сном смешного человека» в том, что герои шекспировского «Сна» тоже попадают из мегаполиса, как мы бы сейчас сказали, - т. е. из Афин, на природу, в волшебный лес, наполненный бессмертными сказочными существами, живущими вроде бы гармоничной жизнью, но потенциально тоже подверженными людским порокам. Аюбовь Аизандра и Гермии, Аеметрия и Елены, пройдя - не скажу через испытания, ибо от их воли мало что зависит в мире, где все управляется колдовством царя фей и эльфов Оберона, но через разные приключения и волшебные преображения, случающиеся с ними, - в итоге завершается счастливым финалом. Внутри пьесы разыгрывается «прежалостная комедия» (the most lamentable comedy) (Шекспир, 1958: 142) или «веселая трагедия в стихах» (very tragical mirth) (там же: 196) о любви Пирама и Фисбы. И хотя здесь все вроде бы делается для вящего веселья и даже лев перед своим появлением предупреждает, что он вовсе не лев, чтоб не испугать никого, но вышеприведенные оксюмороны становятся все значимее к финалу. «Я точно вижу разными глазами (в оригинале parted eуe. - K. C.), // Когда двоится все», говорит Гермия (там же: 191). Перед нами - условный мир пьесы, действие которой происходит в условном сказочном лесу, а под конец разворачивается уже до смешного условное представление о Пираме и Фисбе - и потому столь впечатляюще выглядит контраст с действительной жизнью, обнажаемый в конце. Среди счастливых влюбленных пар и всеобщего ликованья появляется Пэк, маленький эльф, и произносит свой монолог, призванный напомнить зрителю-читателю, что за пределами волшебной театральной коробки - «пустого сновиденья» (no more yielding but a dream) - идет подлинная жизнь, и там:

\footnotetext{
Вот голодный лев рычит, И на месяц воет волк. Утомленный пахарь спит. Труд окончен, шум замолк. Гаснут рдяные дрова, В темноте кричит сова, И больному крик тот злобный Предвещает холм надгробный. Час настал, чтоб на погосте Разверзалась пасть гробов. Возле церкви всюду гости Бродят тени мертвецов
}

(там же: 207).

А под конец Пэк еще раз предлагает зрителям воспринять все происходящее как сон и радуется тому, что своим представлением «мы <...> злобных змей не разбудили» (там же: 209). Однако это не может помешать нам задуматься о том, что хотя колдовством, соком чудесного цветка и прочим можно преобразовать ненависть в любовь и даже ад в рай, но уж больно легко все это происходит с людьми в волшебном царстве Оберона, и как быстро возникает в людях зло, а рай преображается в ад 
и ненависть друг к другу. Но что же в них самих способно противостоять злу в себе и в мире? Һюбовь? Но она здесь - порождение случая, мало того - одновременно с любовью возникает и ненависть, а сон лишь является переходом из одного состояния в другое. Ответа, таким образом, нет. Вдобавок внутри пьесы заключена пародия на евангельский сюжет, когда группа мастеровых, готовящих придворный спектакль, лишившись своего вожака Основы, пребывает в растерянности, но Основа, побывав ослом (символ Христа), возвращается к ним, к их радости (перед этим перевирая евангельское обещание райского блаженства: «Глаз человеческий не слыхал, ухо человеческое не видало...» (там же: 191-192) - того сна, в котором он побывал).

В «Перикле», «Цимбелине»и «Зимней сказке»мы видим как бы чудо воскрешения мертвой. Но в том-то и дело, что «как бы». В «Перикле» чудо объясняется искусством врачевания, которое позволяет уже почти умершую вернуть к жизни, в «Цимбелине» - замечательным свойством снадобья, дающим возможность какое-то время выглядеть умершим, не умирая при этом, в «Зимней сказке» оживает погубленная царем Гермиона, но зрителю внушается, что речь идет лишь о хитрости: верная служанка прятала Гермиону в течение многих лет, а потом вернула ее мужу под видом ожившей статуи. Соответственно, нет и победы над смертью, утверждения вечной жизни.

Но наибольшую остроту проблемы последнего периода творчества Шекспира приобретают в «Буре». Главный герой «Бури» Просперо вроде бы уже достиг того, о чем мечтали герои-богоборцы Шекспира: с помощью волшебства имеет возможность спасать людей от неминуемой смерти и преображать зло в добро, обращать злодеев к покаянию и праведной жизни, провидеть будущее и даже возвращать мертвецов из могил. Но все это, как мы понимаем, не принесло ему счастья и ответов на главные вопросы человеческой жизни. Среди собранных Просперо после кораблекрушения на своем острове человеческих типов честных и добрых практически нет, выделяется среди них, пожалуй, только Гонзало, «старый честный советник короля Неаполитанского» (Шекспир, 1960: 120). Это ренессансный философ, мечтающий о том, что если бы он оказался королем әтого острова, то устроил бы здесь нечто вроде «золотого века» (и даже «превзошел»его) или бытия человечества на «планете Солнца»: «Науками никто б не занимался, // Я б уничтожил бедность и богатство, // 3десь не было бы ни рабов, ни слуг... <...> Никто бы не трудился: ни мужчины, // Ни женщины. Не ведали бы люди // Металлов, хлеба, масла и вина, // Но были бы чисты. Никто над ними // Не властвовал бы...», «Сама природа щедро бы кормила // Бесхитростный, невинный мой народ», «Не было бы здесь // Измен, убийств, ножей, мечей и копий...»; и семей бы не было - ибо брак это тоже труд. Но собеседники подвергают эти его мечтания насмешкам: «Никто <..> не властвовал бы» - а начал с того, что хотел бы быть королем, никто бы ничем не занимался и не было бы браков - значит, перед нами «толпа бездельников и свора шлюх» (там же: 155). Читал ли Н. Г. Чернышевский эту шекспировскую пьесу? То, что у Шекспира отсутствовали всякие ренессансные иллюзии, доказывает и маленький мирок острова Просперо. Мудрый волшебник, приобретший свои умения не посредством чуда, а с помощью книг, т. е. знания, он вроде бы старается вести всех к благу. Но в свое время его излишнее доверие разбудило зло в его младшем брате Антонио, коварством захватившем власть, а теперь здесь, на острове, добрый дух Ариэль рвется от Просперо на свободу, однако принужден служить по условиям договора, злой Калибан ненавидит и боится его - кстати, именно 
с мифическим Полифемом сравнивает Калибана Э.А. Натолл (Nuttall, 2007: 366), а люди, спасенные им после кораблекрушения, все до одного стремятся к злу и бывают остановлены только силой его волшебства. (Правда, дочь Просперо Миранда, не видевшая прежде людей, кроме своего отца, при виде этой толпы негодяев и пьяниц воскдицает: «Как род людской красив! И как хорош // Тот новый мир, где есть такие люди!» (Шекспир, 1960: 205), а Калибан, обольщенный вином, готов обожествить пьяницу-дворецкого Стефано и целовать ему ноги - как «смешной» «детям Солнца»). Но самому Просперо становится тягостна эта работа - «тащить злодеев из болота», как сказали бы мы сейчас. Тем более что и он, как и «смешной», полагает, что вся наша жизнь и есть сон: «Мы созданы из вещества того же, // Что наши сны. И сном окружена // Вся наша маленькая жизнь» ("We are such stuff // As dreams are made on, and our little life is // Is rounded with a sleep" (Shakespeare, 1999: 254)), и весь мир земной когда-нибудь растает, «словно дым» (Шекспир, 1960: 192). Характерно, что так он говорит, когда вынашивает план мести. Затем Просперо, правда, отказывается от первоначального плана отомстить своим врагам, но идиллии не наступает. Так, он заявляет Антонио: «...чтоб уст не осквернить, // Тебя назвать я братом не хочу...» (там же: 203) (вспомним здесь слова из «Братьев Карамазовых»: «Были бы братья, будет и братство...» (Аостоевский, 1976: 286)). Отказавшись в итоге от волшебной власти над миром, Просперо решает возвратиться в свое Миланское герцогство, где, как признается, «каждой третьей моей мыслью будет мысль о смерти» (перевод мой. $-K$. C.; "Every third thought shall be my grave" (Shakespeare, 1999: 284)). "And my ending is despair, // Unless I be relieved by prayer..." (ibid: 286) - такова одна из последних фраз финального монолога несомненно автобиографического героя Просперо, с которой Шекспир совсем скоро уходит из творчества и из жизни. «Шекспир - поэт отчаянья», - писал Аостоевский (Аостоевский, 1982: 162).

Но значит ли это, что у Шекспира отсутствовал идеал? Аумаю, что сказать так было бы неверно. Идеал Шекспира проявляется апофатически. Уже было неоднократно обращено внимание, что Шекспир, особенно в своих трагедиях, как бы сжимает времена (пушки в «Макбете» в XI в., монастыри и Валентинов день в Аревней Греции и т. п.). Но дело, конечно, не в этих деталях, а в том, что Шекспир, как «смешной» в своем сне, «пролетает сквозь тысячелетия» или, говоря словами Бахтина, максимально насыщает пространство временем (Бахтин, 1997: 55). Происходящее здесь и сейчас приобретает, таким образом, черты вечности, мистериальную значимость. Но есть здесь и другой аспект. Порой Шекспир истории, происходившие в языческие времена, переносит во времена христианские (как в «Гамлете», к примеру): вроде бы в схожих обстоятельствах образ мыслей и поведение людей, «во Христа облекшихся», должны меняться - но нет, большей частью они остаются языческими. Присутствие Христа проявляется у Шекспира через Его отсутствие. И тогда остается только уповать на милосердие людей друг к другу, душевное смирение и всепрощение, приходящие на смену мести, - это доминанта последних пьес Шекспира. «Все грешны, все прощенья ждут. // Аа будет милостив ваш суд» (Шекспир, 1960: 212) (а буквально: «Если вы прощены будете, то простите и меня») - таковы финальные строки «Бури». Вот, наверно, идеал Шекспира, во всяком случае, к концу его творческого пути. Вспомним опять-таки слова из «Братьев Карамазовых»: «Пусть я грешен пред всеми, зато и меня все простят, вот и рай» (Аостоевский, 1976: 263); ведь «каждый единый из нас виновен за всех и за вся на земле несомненно» (там же: 149), а потому и просить прощения надо «за всех, за все и за вся» (там же: 328$)$. 


\section{ЗАКАЮЧЕНИЕ}

Именно здесь, в духовном единении людей через всепрощение, видится то, что сближает идеалы двух гениев мировой литературы. Но Аостоевский подчеркивает необходимость преображения человека на пути к идеалу, в то время как Шекспир уповал более на добрые начала, уже заложенные в человеческой природе.

\section{СПИСОК АИТЕРАТУРЫ}

Бахтин, М. М. (1997) Собр. соч. : в 7 т. М. : Русские словари. Т. 5: Работы 1940-х - начала 1960-х годов. $731 \mathrm{c.}$

Бахтин, М. М. (2002) Собр. соч. : в 7 т. М. : Русские словари ; Языки славянской культуры. Т. 6: Проблемы поэтики Аостоевского, 1963. Работы 1960-х - 1970-х гг. 799 с.

Бахтин, М. М. (2003) Собр. соч. : в 7 т. М. : Русские словари ; Языки славянской культуры. Т. 1: Философская эстетика 1920-х гг. 957 с.

Белинский, В. Г. (1978) Собр. соч. : в 9 т. М. : Художественная литература. Т. 3: Статьи, рецензии, заметки. Февраль 1840 - февраль 1841. 614 с.

Аостоевский, Ф. М. (1974) Полн. собр. соч. : в 30 т. $\Lambda$. : Наука, Аенингр. отд-ние. Т. 11: Бесы : Глава «У Тихона» : Рукописные редакции. 416 с.

Аостоевский, Ф. М. (1976) Полн. собр. соч. : в 30 т. А. : Наука, Аенингр. отд-ние. Т. 14: Братья Карамазовы. Книги I-X. 512 с.

Аостоевский, Ф. М. (1980) Полн. собр. соч. : в 30 т. А. : Наука, Аенингр. отд-ние. Т. 20: Статьи и заметки $1862-1865.432$ с.

Аостоевский, Ф. М. (1981) Полн. собр. соч. : в 30 т. А. : Наука, Аенингр. отд-ние. Т. 22: Аневник писателя за 1876 год, январь - апрель. 408 с.

Аостоевский, Ф. М. (1982) Полн. собр. соч. : в 30 т. А. : Наука, Аенингр. отд-ние. Т. 24: Аневник писателя за 1876 год, ноябрь - декабрь. 520 с.

Аостоевский, Ф. М. (1983) Полн. собр. соч. : в 30 т. А. : Наука, Аенингр. отА-ние. Т. 25: Аневник писателя за 1877 год, январь - август. 472 с.

Шекспир, У. (1958) Полн. собр. соч. : в 8 т. М. : Искусство. Т. 3.567 с.

Шекспир, У. (1960) Полн. собр. соч. : в 8 т. М. : Искусство. Т. 8. 636 с.

Хьюз, Т. (2014) Шекспир и Богиня Полноты бытия : фрагменты книги / пер. и вступл. А. Мясниковой // Иностранная литература. № 5. С. 97-108.

Nuttall, A. D. (2007) Shakespeare the Thinker. New Haven, CT ; London : Yale University Press. $428 \mathrm{p}$.

Shakespeare, W. (1999) The Tempest / ed. by V. M. Vaughan, A. T. Vaughan. London : Arden Shakespeare. $366 \mathrm{p}$.

Аата поступления: 12.06.2015 г.

THE IDEAL IN DOSTOEVSKY AND SHAKESPEARE

\section{K. A. STEPANYAN}

(ZNAMYA LITERARY MAGAZINE, MOSCOW)

This paper examines the views of two great authors - a Russian and an Englishman - on such issues as the possibility and means of victory over death and over evil in human soul; the chance for happy future for mankind on earth, within the limits of worldly history. These views are mainly examined as they are expressed in Fyodor M. Dostoevsky's 'fantastic story' "The Dream of a Ridiculous Man" and in William Shakespeare's "A Midsummer Night's Dream" and "The Tempest". Fantasies and dreams are a traditional literary device which most completely and freely reveals writers' ideals (or warns against the possible triumph of their anti-ideals). But what such true (metaphysical) realists as Dostoevsky and Shakespeare present is an in-depth analysis of challenges and roadblocks on the way to human happiness. 
The abovementioned texts will be examined in the context of Dostoevsky's and Shakespeare's entire bodies of work (their changing philosophical stance as they evolved creatively and their artistic means to express that stance); against the backdrop of the Golden Age concepts in human culture; and with respect to the role that art should and can play in transforming human nature. The paper will also analyze how Dostoevsky and Shakespeare agree or disagree on these issues, - in particular, how they disagree in their interpretation of the 'Thou shalt love thy neighbor as thyself' commandment (considering what Mikhail M. Bakhtin said on the subject) and in general, in interpreting the phenomenon of human love.

Dostoevsky's ideal is a human being who overcomes his sins through spiritual evolution, and mankind, which in the course of history achieves spiritual unity and transfiguration into a community of new fellowship. Shakespeare's ideal occurs in some ways apophatically. The characters of his works, most of them living in the Christian centuries, still remain heathens; that is the essence of their tragic guilt. The presence of Christ is perceived by His absence. And the only hope is for human mercy and forgiveness.

Keywords: ideal; F. M. Dostoevsky; W. Shakespeare; M. M. Bakhtin; "The Dream of a Ridiculous Man"; "A Midsummer Night's Dream"; "The Tempest"

\section{REFERENCES}

Bakhtin, M. M. (1997) Sobranie socbinenii [Collected Works] : in 7 vols. Moscow, Russkie slovari Publ. Vol. 5: Raboty 1940-kb - nachala 1960-kb godov [Works of the 1940s - early 1960s]. $731 \mathrm{p}$. (In Russ.).

Bakhtin, M. M. (2002) Sobranie socbinenii [Collected Works] : in 7 vols. Moscow, Russkie slovari Publ. ; Iazyki slavianskoi kul'tury Publ. Vol. 6: "Problemy poetiki Dostoevskogo», 1963. Raboty 1960-kb-1970-kb gg. ["Problems of Dostoevsky's Poetics", 1963. Works of the 1960s-1970s]. 799 p. (In Russ.).

Bakhtin, M. M. (2003) Sobranie socbinenii [Collected Works] : in 7 vols. Moscow, Russkie slovari Publ. ; Iazyki slavianskoi kul'tury Publ. Vol. 1: Filosofskaia estetika 1920-kb gg. [Philosophical aesthetics of the 1920s]. 957 p. (In Russ.).

Belinsky, V. G. (1978) Sobranie socbinenii [Collected Works] : in 9 vols. Moscow, Khudozhestvennaia literatura Publ. Vols. 3: Stat'i, retsenzii, zametki. Fevral' 1840 - fevral' 1841 [Articles, reviews, notes. February 1840 - February 1841]. 614 p. (In Russ.).

Dostoevsky, F. M. (1974) Polnoe sobranie socbinenii [Complete works] : in 30 vols. Leningrad, Nauka Publ., Leningrad Branch. Vol. 11: Besy : Glava «U Tikhona» : Rukopisnye redaktsii [Demons : Chapter "At Tikhon's" : Manuscript versions]. 416 p. (In Russ.).

Dostoevsky, F. M. (1976) Polnoe sobranie socbinenii [Complete works] : in 30 vols. Leningrad, Nauka Publ., Leningrad Branch. Vol. 14: Brat'ia Karamazovy. Knigi I-X [The Brothers Karamazov. Books I-X]. 512 p. (In Russ.).

Dostoevsky, F. M. (1980) Polnoe sobranie sochinenii [Complete works] : in 30 vols. Leningrad, Nauka Publ., Leningrad Branch. Vol. 20: Stat'i i zametki 1862-1865 [Articles and notes 1862-1865]. 432 p. (In Russ.).

Dostoevsky, F. M. (1981) Polnoe sobranie sochinenii [Complete works] : in 30 vols. Leningrad, Nauka Publ., Leningrad Branch. Vol. 22: Dnevnik pisatelia za 1876 god, ianvar' - aprel' [Writer's diary, 1876, January - April]. 408 p. (In Russ.).

Dostoevsky, F. M. (1982) Polnoe sobranie socbinenii [Complete works] : in 30 vols. Leningrad, Nauka Publ., Leningrad Branch. Vol. 24: Dnevnik pisatelia za 1876 god, noiabr' - dekabr' [Writer's diary, 1876, November - December]. 520 p. (In Russ.).

Dostoevsky, F. M. (1983) Polnoe sobranie sochinenii [Complete works] : in 30 vols. Leningrad, Nauka Publ., Leningrad Branch. Vol. 25: Dnevnik pisatelia za 1877 god, ianvar' - avgust [Writer's diary, 1877, January - August]. 472 p. (In Russ.).

Shakespeare, W. (1958) Polnoe sobranie sochinenii [Complete works] : in 8 vols. Moscow, Iskusstvo Publ. Vol. 3.567 p. (In Russ.). 
Shakespeare, W. (1960) Polnoe sobranie socbinenii [Complete works] : in 8 vols. Moscow, Iskusstvo Publ. Vol. 8. 636 p. (In Russ.).

Hughes, T. (2014) Shekspir i Boginia Polnoty bytiia [Shakespeare and the Goddess of Complete being] : fragments of the book / transl. and introduction by A. Miasnikova. Inostrannaia literatura, no. 5, pp. 97-108. (In Russ.).

Nuttall, A. D. (2007) Shakespeare the Thinker. New Haven, CT ; London, Yale University Press. $428 \mathrm{p}$.

Shakespeare, W. (1999) The Tempest / ed. by V. M. Vaughan and A. T. Vaughan. London : Arden Shakespeare. $366 \mathrm{p}$.

Submission date: 12.06 .2015 .

Степанян Карен Ашотович - доктор филологических наук, заведующий отделом критики журнала «Знамя», вице-президент российского Общества Аостоевского. Адрес: 121069, Россия, г. Москва, ул. Большая Садовая, д. 2/46. Тел.: +7 (495) 699-48-71. Эл. адрес: stepanyan@bk.ru

Stepanyan Karen Ashotovich, Doctor of Philology, Head of the Criticism Department, Znamya Literary Magazine; Vice President, Russian Dostoevsky Society. Postal address: 2/46 Bolshaya Sadovaya St., 121069 Moscow, Russian Federation. Tel.: +7 (495) 699-48-71. E-mail: stepanyan@bk.ru 